\title{
Chloride Penetration through Cracks in High-Performance Concrete and Surface Treatment System for Crack Healing
}

\author{
In-Seok Yoon \\ Department of Construction Information Engineering, Induk University, Seoul 139-749, Republic of Korea \\ Correspondence should be addressed to In-Seok Yoon, isyoon@induk.ac.kr
}

Received 16 December 2011; Accepted 1 February 2012

Academic Editor: Jin Ping Lu

Copyright () 2012 In-Seok Yoon. This is an open access article distributed under the Creative Commons Attribution License, which permits unrestricted use, distribution, and reproduction in any medium, provided the original work is properly cited.

For enhancing the service life of concrete structures, it is very important to minimize crack at surface. Even if these cracks are very small, the problem is to which extend these cracks may jeopardize the durability of these decks. It was proposed that crack depth corresponding with critical crack width from the surface is a crucial factor in view of durability design of concrete structures. It was necessary to deal with chloride penetration through microcracks characterized with the mixing features of concrete. This study is devoted to examine the effect of high strength concrete and reinforcement of steel fiber on chloride penetration through cracks. High strength concrete is regarded as an excellent barrier to resist chloride penetration. However, durability performance of cracked high strength concrete was reduced seriously up to that of ordinary cracked concrete. Steel fiber reinforcement is effective to reduce chloride penetration through cracks because steel fiber reinforcement can lead to reduce crack depth significantly. Meanwhile, surface treatment systems are put on the surface of the concrete in order to seal the concrete. The key-issue is to which extend a sealing is able to ensure that chloride-induced corrosion can be prevented. As a result, penetrant cannot cure cracks, however, coating and combined treatment can prevent chloride from flowing in concrete with maximum crack width of $0.06 \mathrm{~mm}$ and $0.08 \mathrm{~mm}$, respectively.

\section{Introduction}

Over the last decades, many improvements have been presented in both measuring techniques and modeling of ionic flows in the field of chloride penetration. However, the majority of this research has been performed on sound uncracked concrete, even though many in situ concrete structures have more or less micro-cracks. Although these microcracks may not degrade the structural safety immediately, the question is to which extent these cracks may jeopardize the durability of cracked concrete by permitting penetration of aggressive substances into concrete easily. To begin with, moisture penetration through cracks can defeat the purpose of the surface treatment by allowing localized reinforcement corrosion [1]. Especially, penetration of chlorides into concrete through the micro-cracks can make a significant harmful effect on reinforcement corrosion [2]. There are several different reasons for not taking the effect of crack on chloride penetration into account. The most important ones are that it is difficult to make accurate measurements on the flow through cracks and that there are many affecting factors and complexities. Nevertheless, the existent cracks are a reality and it is necessary to deal with the effect of cracks on chloride penetration.

In particular, high-performance concrete (high-strength concrete) can be regarded as a durable material to insure a long service life, as long as there are no cracks. Barrier function to protect high-strength concrete is severely broken, however, if a crack is generated. Since high-strength concrete is more brittle than ordinary concrete, durability design must be accomplished for greater safety. Nevertheless, it is very rare to deal with the issue in the study of high-performance concrete.

Meanwhile, surface treatment system for small cracks and epoxy injection for medium or big cracks have been recommended for crack repair [3]. That is, if the size of the crack is small, surface treatment system can be considered as one of the best options to heal the crack in terms of cost effectiveness versus durability performance and to extend the service life of concrete structures. However, there seems 


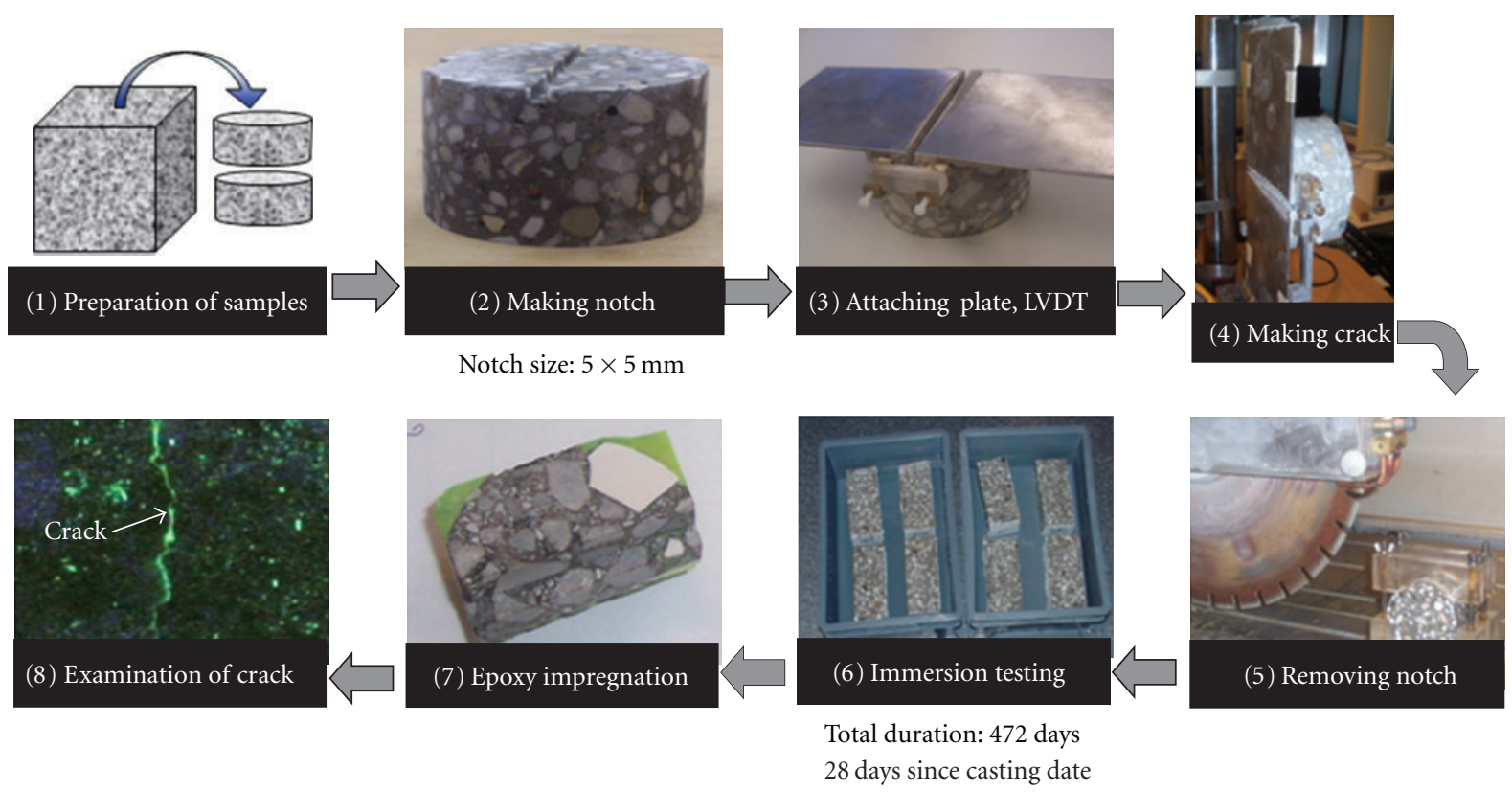

FIGURE 1: Outline of experimental procedures: from making concrete samples to getting data.

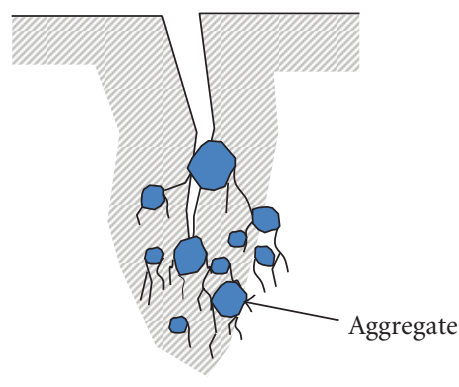

(a) Small size of aggregate

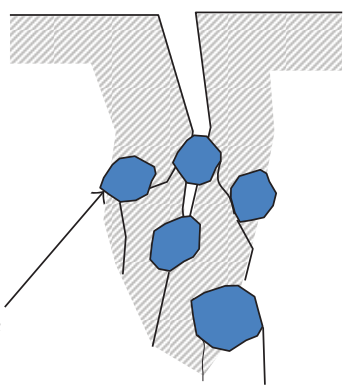

(b) Large size of aggregate

FIGURE 2: Effect of size of coarse aggregate on microcracking.

to be no research to explain technical limitation of surface treatment system, in particular, critical crack width which can be healed by the system $[4,5]$. ACI [6], JCI [7], and KISTEC [8] just suggested that low solids and low-viscosity resin-based systems are useful to cure fine cracks. However, the limitation of surface treatment system as a crack repair method should be understood. That is, it is necessary to define the scale of the crack that can be healed by the method, in order to make sure of the reliability of the crack repair method.

The purpose of this study is to examine the effect of microcracks on chloride penetration in cracked HPC and study the efficiency of certain surface treatments for the crack healing. Accelerating experiment was carried out to investigate the effect of surface treatment systems to enhance service life of cracked concrete. For plain concrete and surface treated concrete, the critical crack size that can be healed by surface treatment systems is examined. Cracks smaller than this critical crack size are considered not to

TABLE 1: Material properties of penetrant (PT).

\begin{tabular}{lc}
\hline Items & Value \\
\hline Main ingredient & Silane \\
Turbidity & below 1.0 \\
Ratio of water sorptivity (KSF 4930) & 0.05 \\
Color & Colorless \\
pH & 8.3 \\
Type & Liquid \\
\hline
\end{tabular}

have a significant influence on the rate of chloride transport inwards, while chloride penetration does proceed faster above the critical crack size.

\section{Experiment Program}

\subsection{Program I: Chloride Penetration through Cracks in HPC}

2.1.1. Preparation of Concrete Samples and Cracking. All steps for experiment program are depicted in Figure 1. Mixing proportion is given in Table 1. For comparison with highperformance concrete (HPC), OPC samples were made with ordinary Portland cement, water/cement ratio of 0.50 . OPC samples had two types with maximum size of coarse aggregate: $8 \mathrm{~mm}$ and $16 \mathrm{~mm}$. It is well known that interfacial transition zone (ITZ) between cement paste and aggregate forms a more porous framework than bulk cement paste. Since ITZ is considered as the weakest link of the chain, cracks are preferentially propagated in concrete under compressive or tensile stress. The crack propagation depends on the size of coarse aggregate, as shown in Figure 2. Cracking is very complicated in concrete with the small size of coarse 
aggregate and this is intended in two types of OPC concrete samples.

HPC samples were mixed with fly ash and silica fume and its 28-day strength was equivalent to $100.1 \mathrm{Mpa}$. HPFRC samples mean high-strength concrete reinforced by steel fiber. Steel fiber can lead to complicated cracks and cracks bridging in the concrete. This was intended for investigation on chloride penetration through the complicated cracks in HPFRC samples.

The concrete was cast into $150 \times 150 \times 150 \mathrm{~mm}$ cube moulds, which were moist-cured at $20^{\circ} \mathrm{C}$ for 48 hours, followed by air exposure at a relative humidity of $65 \%$ and $20^{\circ} \mathrm{C}$. Sample series and preparation were set up in such a way that the specimens could be tested for chloride penetration at an age of 28 days. In these specimens, a notch was made of $5 \mathrm{~mm}$ wide and $5 \mathrm{~mm}$ depth. Next to the notch steel plates were glued to introduce the tensile forces to create a fracture.

To control the crack formation, two LVDTs were fixed on each side of the specimen, perpendicular to the loading direction, to monitor the crack mouth opening displacement (CMOD). The tests were performed in deformation control mode up to the target CMOD. Then the specimen was unloaded and taken out of the machine. Time, force, stroke, and CMOD were recorded during the test. The effective CMOD value (i.e., the unloaded value) was used in the analysis and graphical plots. After unloading but before performing the RCM test the notch had been cut off, to arrive at a sample thickness of $50 \mathrm{~mm}$.

2.1.2. Chloride Penetration Experiment. Rapid chloride migration (RCM) test, standardized in NordTest NT-Build 492 [9], has been used more and more to investigate pene-tration of chloride into concrete. This is set up as a non-steady-state migration test. These are then used to help design concrete materials for long-lasting structures. In such design process ordinary crack-free concrete was considered; however, this experiment was effective to quantify the effect of cracks on chloride penetration. One side of the sample was exposed to a salt solution, while the other side of the sample was exposed to a $0.3 \mathrm{~N} \mathrm{NaOH}$ solution. Using stainless steel plate electrodes on both sides of the sample, a DC voltage was applied to force the negatively charged chloride ions through the sample. After the test the samples were split and sprayed with $0.01 \mathrm{~N} \mathrm{AgNO}_{3}$ solution to visualize the ingress of chloride into the sample.

Since it is the purpose of this research to investigate the influence of micro-cracks on the penetration of chloride, the RCM test has been performed on fractures samples after 28 days. The introduction and formation of cracks are described later in this paper. The expected end result of an RCM test is given in Figure 3. Chloride penetration depth in the unfractured zone $\left(d_{1}\right)$ and the fractured zone $\left(d_{T}\right)$ was measured and the values were used for chloride diffusion coefficient in the unfractured zone $\left(D_{1}\right)$ and the fractured zone $\left(D_{T}\right)$.

2.2. Program II: Crack Healing to Prevent Chloride Penetration. Surface treatment systems can be classified into three

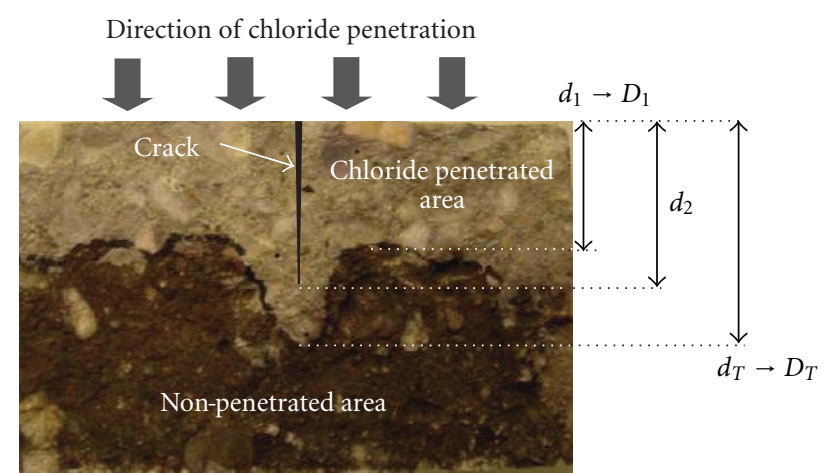

FIGURE 3: Schematic end result of the RCM test on fractured specimen, with different notation codes.

TABLE 2: Material properties of coating material (CT).

\begin{tabular}{lc}
\hline Items & Value \\
\hline Main ingredient & Polymer \\
Bonding strength $(\mathrm{Mpa})$ & 2.12 \\
Color & Light grey \\
Type & powder + water \\
\hline
\end{tabular}

types: (a) penetrant, whereby surface near zone is impregnated and dense layer with pore blocker is formed, (b) coating, whereby in most cases a thin or thick continuous membrane polymer film is applied, and (c) sealer, whereby properties of both the penetrant and coating can be expected. Figure 4 illustrates these three groups of protection.

After generating cracks in OPC samples, surface treatment system was applied in the surface. In the experiment, penetrant and coating material were used and materials properties are shown in Tables 2 and 3. For penetrant, the achievable penetration depth in concrete mainly depends on four factors: the type of hydrophobic agent applied, the W/C of the concrete substrate, the initial moisture content, and the surface preparation of the concrete substrate [10].

Thickness of surface coating was measured by a microscope and the value was about $70 \mathrm{um}$, as shown in Figure 5. Samples treated with penetrant were split and sprayed with water. Then the penetration depth was measured and the value was $2.8 \mathrm{~mm}$.

\section{Result and Discussion}

3.1. Chloride Penetration through Cracks. Figure 6 represents the relative diffusivity $\left(D_{T} / D_{1}\right)$ of concrete with various sizes of coarse aggregate. The relative diffusivity of concrete with $G_{\max } 16 \mathrm{~mm}$ tends to be higher than that of concrete with $G_{\max } 8 \mathrm{~mm}$, however, the trend is not significant. Although micro-cracks are concentrated at the surface of coarse aggregate, the cracks do not influence chloride penetration. Since the micro-cracks are smaller than $0.012 \mathrm{~mm}$, which is a critical crack width in accordance with a previous research of author, the crack is thought not to be effective for chloride penetration [11]. According to the study, chloride ions cannot immediately penetrate all the way up to the 


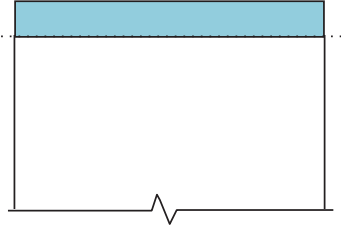

(a) Coating

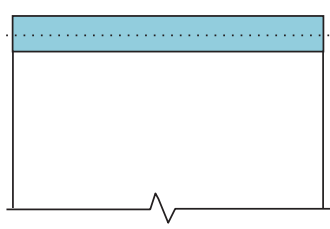

(b) Sealer

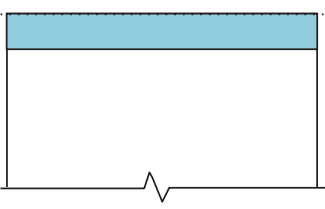

(c) Penetrant

Surface treatment

Concrete

FIgURE 4: Type of surface treatment systems.

TABLE 3: Mixing proportion of concrete.

\begin{tabular}{|c|c|c|c|c|c|c|c|c|}
\hline \multirow{2}{*}{ Mix symbol } & \multirow{2}{*}{ 28-day strength $(\mathrm{MPa})$} & \multirow{2}{*}{$\mathrm{W} / \mathrm{C}$} & \multirow{2}{*}{$G_{\max }(\mathrm{mm})$} & \multicolumn{5}{|c|}{ Unit weight $\left(\mathrm{kg} / \mathrm{m}^{3}\right)$} \\
\hline & & & & Water & Cement & Mineral Adx. & Sand & Gravel \\
\hline OPC & 28.5 & 0.50 & 16 & 185 & 370 & - & 720 & 1021 \\
\hline OPC II & 28.5 & 0.50 & 8 & 185 & 370 & - & 720 & 1021 \\
\hline HPC & 100.1 & 0.20 & 8 & 128 & 440 & $\begin{array}{c}\text { Fly ash } 132 \\
\text { Silica fume } 64\end{array}$ & 1045 & 485 \\
\hline HPFRC* & 125.5 & 0.33 & - & 145 & 439 & - & 1912 & - \\
\hline
\end{tabular}

*Volume of steel fiber: $175 \mathrm{~kg} / \mathrm{m}^{3}$ (length: $16 \mathrm{~mm}$, diameter: $0.13 \mathrm{~mm}$ ).

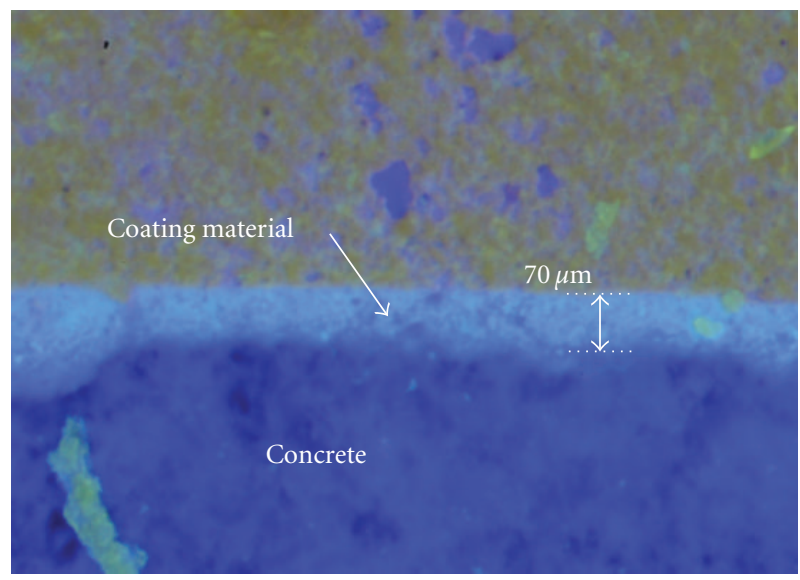

FIGURE 5: Thickness of coating material on surface concrete.

crack tip when the cracked concrete is faced with chloride solution. The rate of penetration decreases with increasing crack depth. This rate of penetration is influenced by the geometrical properties of the cracks. With increasing the depth of the crack, the crack width decreases and, more importantly, the crack is tortuous and has more chance to be unconnected closer to the crack tip, because of crack branching and bridging. Based on the findings in this research, it is necessary to make a strong argument to consider the crack width versus chloride penetration under various tension conditions.

Figure 7 depicts the relative diffusivity of various concrete samples. Compared with OPC, HPC and HPFRC have a high relative diffusivity as if the durability performance

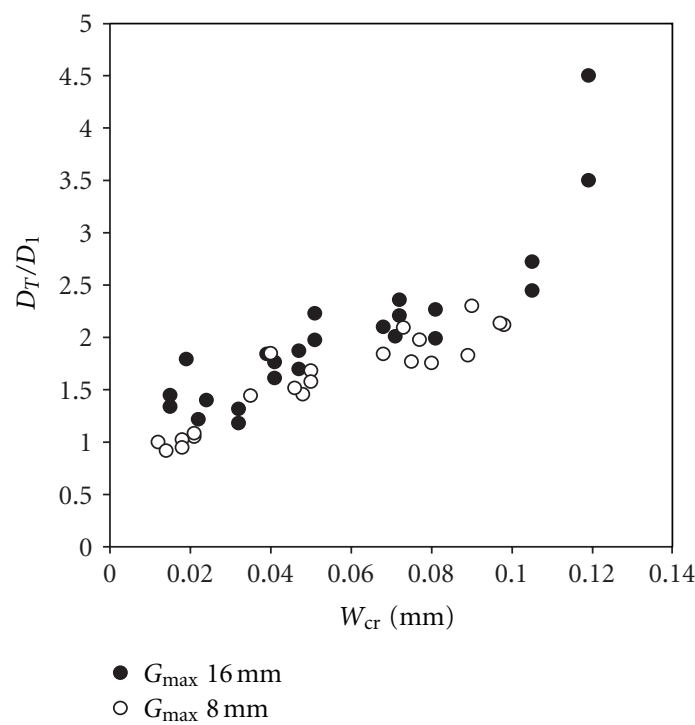

FIgURE 6: Relative diffusivity versus $G_{\max }$.

of HPC/HPFRC is worse than that of OPC. The result is far from previous researches because HPC is recognized as a-high-durability concrete. The reason can be explained by Figures 8 and 10 .

Figure 8 shows the relationship between chloride penetration depth and crack width. HPC and OPC showed the same chloride penetration depth if the crack width is higher than $0.03 \mathrm{~mm}$. Overall, a little chloride penetration is examined at HPC and HPFRC. This is because high strength leads to dense micro-structure of concrete and steel fiber inducing 


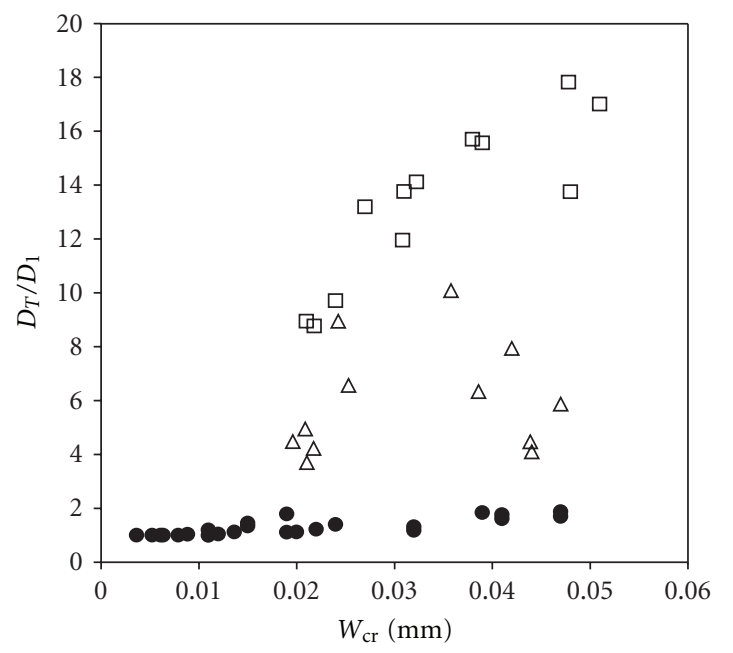

- $\mathrm{OPC}\left(G_{\max } 16 \mathrm{~mm}\right)$

$\square \mathrm{HPC}$

$\triangle$ HPFRC

FIGURE 7: Relative diffusivity versus concrete type.

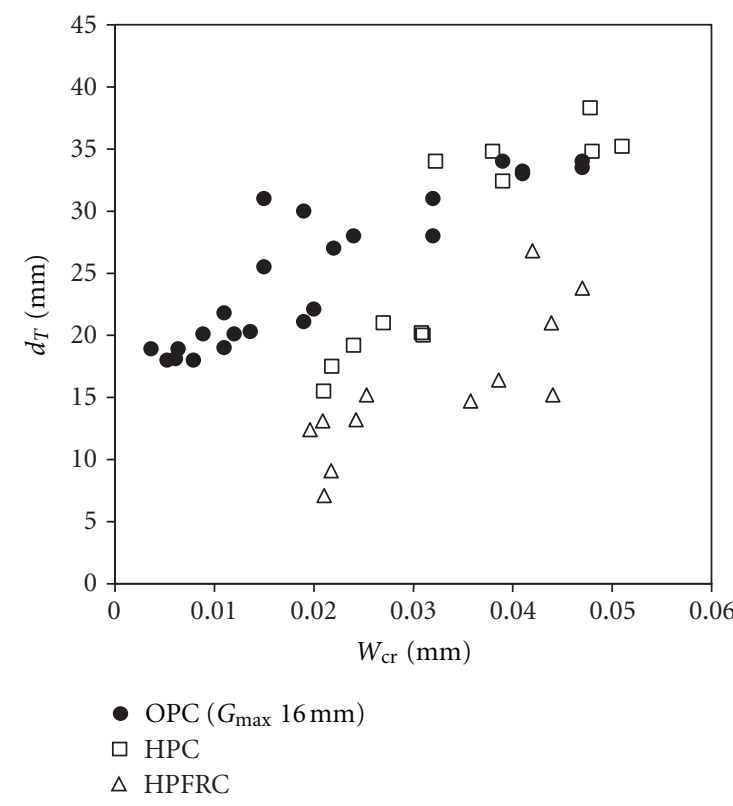

FIGURE 8: Chloride penetration depth versus crack width.

delay strain induced crack propagation. That is to say, steel fiber has a function to increase crack depth, $d_{2}-d_{e}$ (see Figure 9), corresponding with critical crack width $0.012 \mathrm{~mm}$, and to decrease effective crack depth $d_{e}$.

Figure 10 shows a photo of chloride profile in concrete contaminated by chloride ions. Compared with OPC, HPC does not allow chloride penetration. Once cracks are generated, however, HPC loses its high protection performance significantly. This is why relative diffusivity $\left(D_{T} / D_{1}\right)$ of HPC is much higher than that of OPC. HPC without cracks has a very high resistance to deterioration due to chloride penetration; however, HPC is prone to be cracked. If there are

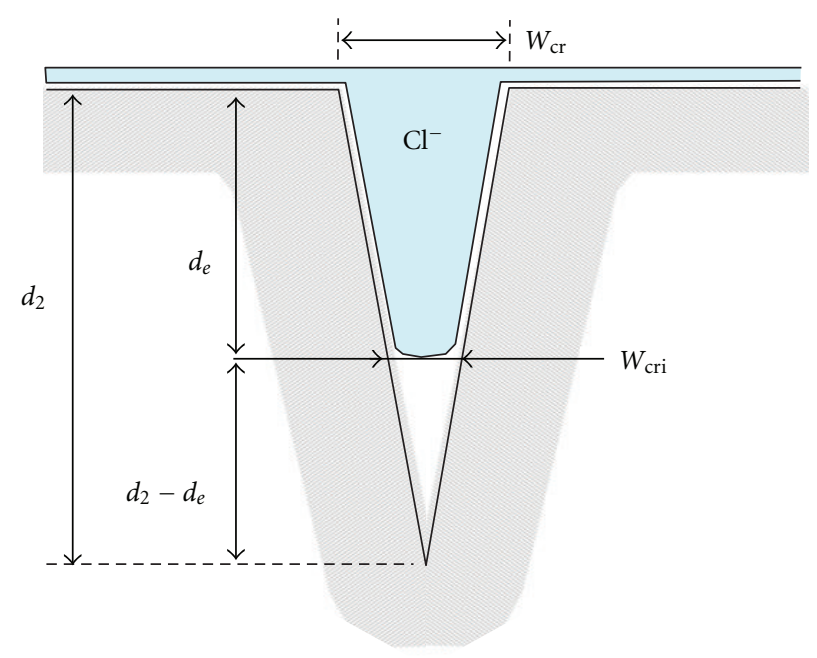

FIGURE 9: Schematic representation of effective crack depth according to critical crack depth.

no cracks in HPC, its service life can be overestimated too much in durability designing. Therefore, the penetration of harmful substances through cracks must be considered in establishing the maintenance strategy of HPC structures under severe conditions.

3.2. Crack Healing Effect. Figure 11 shows chloride diffusion coefficient for penetrant-treated concrete. As expected, the chloride diffusion coefficient of cracked concrete is higher than that of uncracked concrete. From CMOD $0.024 \mathrm{~mm}$, chloride penetration through crack is found. CMOD $0.024 \mathrm{~mm}$ is too small, and, thus, it can be suggested that penetrant is difficult to expect crack healing.

Figure 12 represents chloride diffusion coefficient for CT-treated concrete. Compared with PT-treated concrete, CT-treated concrete showed low diffusion coefficient. This means that the performance of surface coating is better than that of penetrant for chloride resistance. Above all, the experimental result shows obviously that when the crack width was large, beyond around $0.060 \mathrm{~mm}$, the rate of increase of chloride penetration increased. In other words, increasing chloride diffusivity is responsive to $0.060 \mathrm{~mm}$ of CMOD. This means the critical crack opening that can be healed with coating system is $0.060 \mathrm{~mm}$, and this is higher than $0.024 \mathrm{~mm}$, which is a limitation of crack width healed with penetrant. Therefore, it is concluded that coating also does not have a satisfactory performance although coating is better than penetrant for crack healing.

Figure 13 illustrates chloride diffusion coefficient for PCT-treated concrete. Already below a value of CMOD of $0.08 \mathrm{~mm}$ the influence of the crack on the chloride transport starts to become noticeable. The penetrant can lead to dense fracture; however, space between cracks should still exist. If penetrant-treated concrete is coated, membrane coating film is formed and this is effective to protect the concrete from chloride penetration. The double protective system can be believed to cure crack with $0.08 \mathrm{~mm}$ maximum width. This 


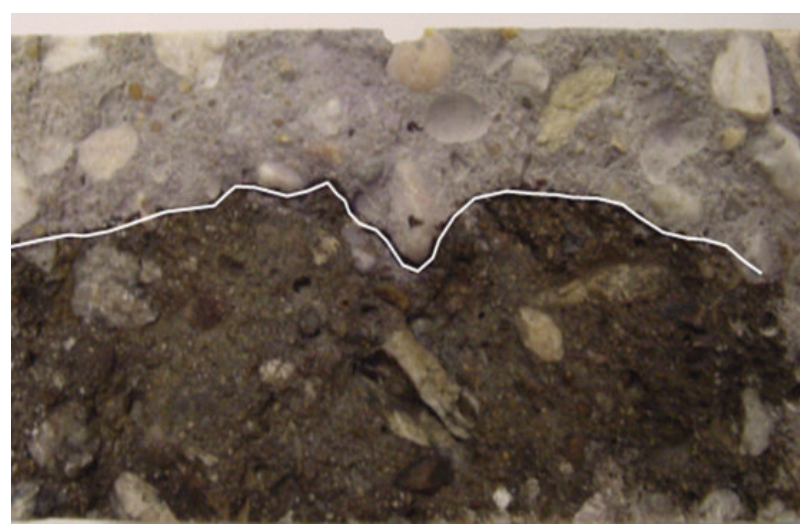

(a) OPC concrete

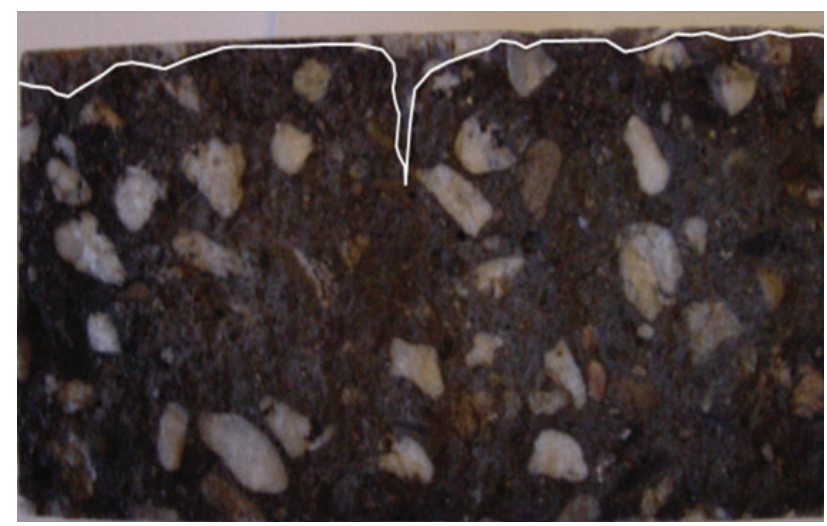

(b) HPC concrete

FIGURE 10: Comparison of chloride profile of OPC concrete with that of HPC concrete.

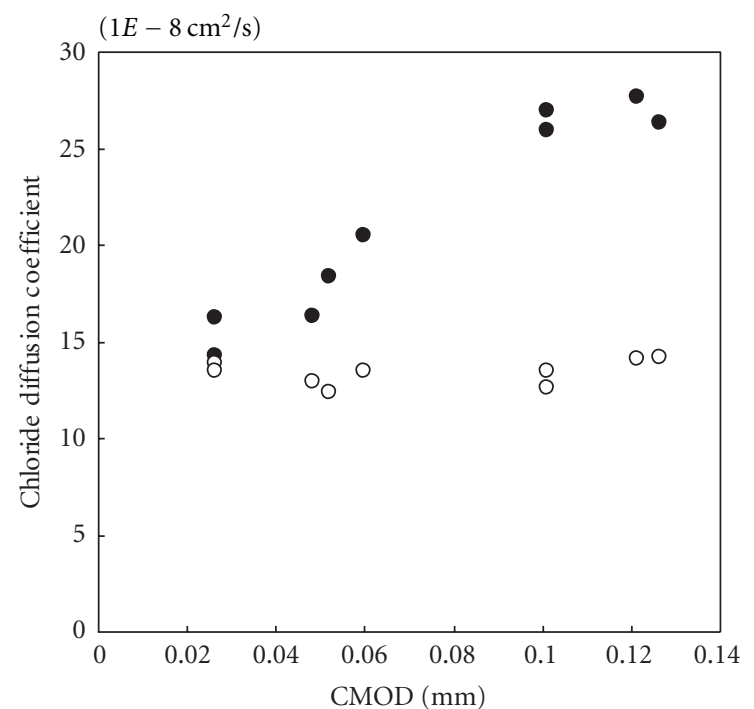

- Cracked zone

- Uncracked zone

FIGURE 11: Chloride diffusion coefficient for PT-treated concrete.

is also not a satisfactory performance for healing. Of course, the critical crack width depends on type of surface treatment system, quality, the number of treatments, number of layers, and so on.

Figure 14 represents the effect of type of surface treatment on the prevention of extra chloride penetration through cracks. There is no doubt that the penetrant cannot cure cracks. This is because the penetrant cannot fill space between crack fractures and does not have significant crackbridging capabilities, although the hydrophobic nature of the material may reduce the intrusion of moisture into narrow cracks. The experimental result shows obviously, however, that the coating system is effective for healing cracks up to maximum CMOD $0.06 \mathrm{~mm}$, the so-called critical crack width that can be healed by surface treatment system. For combined application of the penetrant and coating system, when the CMOD was large, beyond around $0.08 \mathrm{~mm}$, the

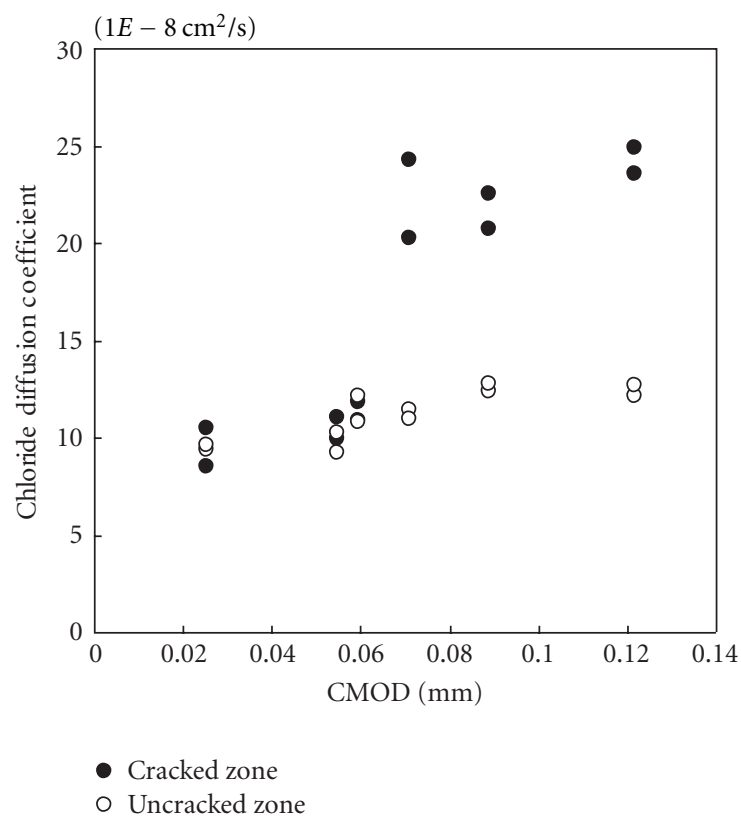

FIGURE 12: Chloride diffusion coefficient for CT-treated concrete.

rate of increase of chloride penetration increased. This means that there is no extra chloride penetration through the crack if the crack width is smaller than $0.08 \mathrm{~mm}$. As a matter of course, the value depends on material properties of surface treatment; however, the value is much smaller than we have expected. The value should lead to extremely conservative criterion. It is difficult to apply to estimation the integrity of in situ concrete structures with a value. JCI [7] and KISTEC [8] recommended the surface treatment method including the penetrant to keep the performance of watertightness for concrete with maximum crack width $0.20 \mathrm{~mm}$. Obviously $0.20 \mathrm{~mm}$ is much higher than the critical crack width of $0.06 \sim 0.08 \mathrm{~mm}$. It is necessary to examine its effective application.

Based on the results of this study, it is concluded that penetrant is not suitable for crack healing and the coating system should be applied after understanding the limitation 


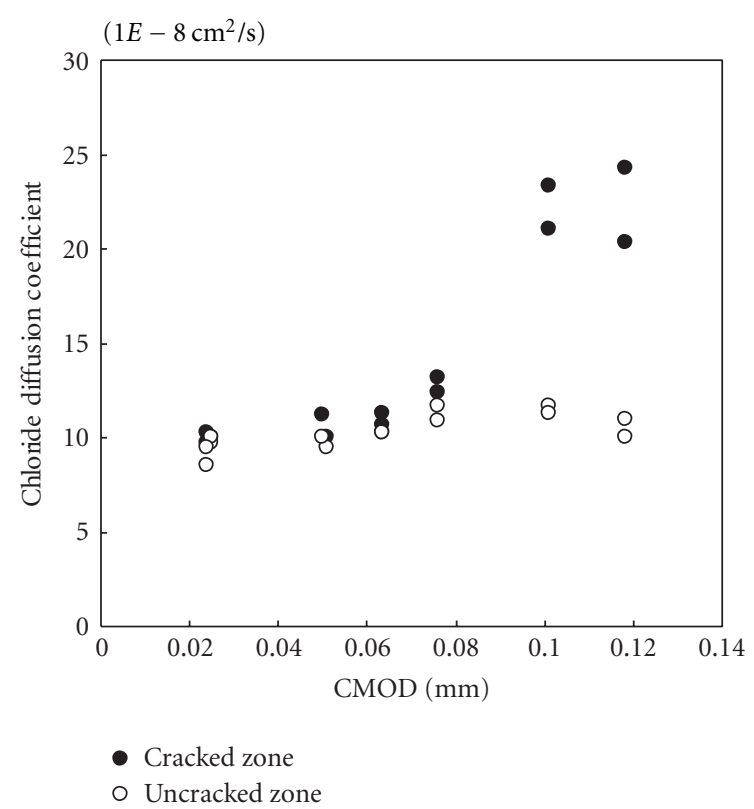

FIGURE 13: Chloride diffusion coefficient for PCT treated concrete.

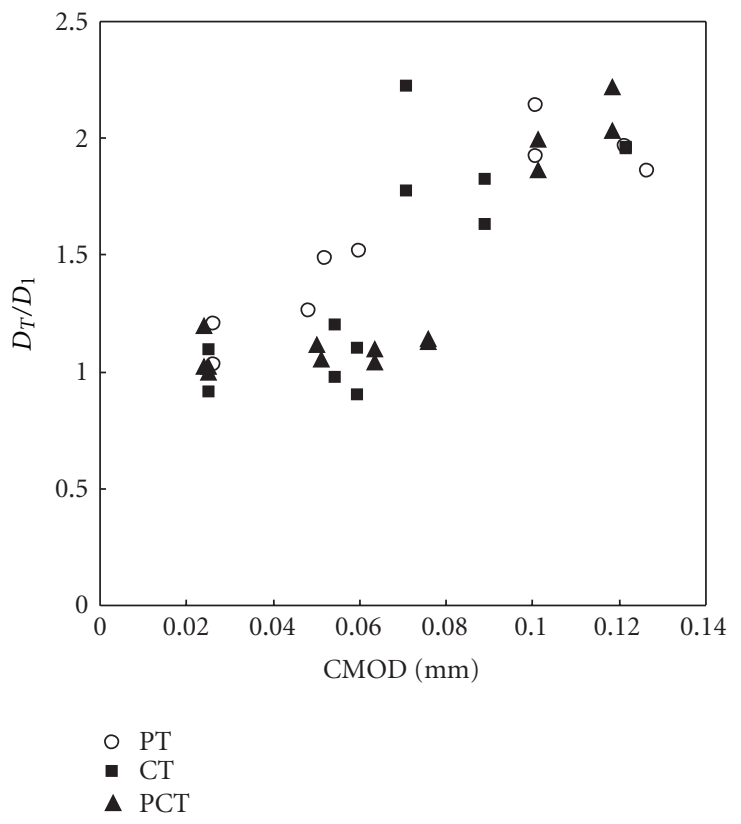

Figure 14: Relative chloride diffusion coefficient $\left(D_{T} / D_{1}\right)$ for surface treated concrete.

of its effectiveness. For verification, the crack healing effect and critical crack width should be examined with the outcome of chloride immersion testing for long term.

This study is expected to provide us with insight into developing design criteria for a durable concrete and in understanding the effect of surface treatment system to repair cracked concrete structure. It is expected that the outcome of this study could be an engineering ground to choose the type of surface treatment system and to judge the durability performance of surface treated concrete. For more research, the capacity to bridge and heal cracks should be carefully studied depending on the type of the surface treatment system and number of coating layers.

\section{Conclusions}

(1) Experiment recipe was designed to investigate chloride penetration through cracks in OPC and HPC concrete. Compared with OPC, HPC did not allow chloride penetration. However, HPC with cracks lost its high protection performance seriously. That is, the relative diffusivity of HPC is much higher than that of OPC. This means that chloride penetration through cracks must be considered in HPC structures exposed to sea water. Steel fiber had a function to increase crack depth and to decrease effective crack depth.

(2) Penetrant cannot cure cracks. However, it was noticed that concrete with maximum crack width $0.06 \mathrm{~mm}$ was healed by coating system. Combination of penetrant and coating system made a positive contribution to crack healing up to maximum crack width $0.08 \mathrm{~mm}$.

\section{Acknowledgment}

This study was sponsored by Induk University, Seoul, Republic of Korea.

\section{References}

[1] ACI Committee 546, Concrete Repair Guide, ACI Manual of Concrete Practice-Part 6, ACI International, 2002.

[2] R. François and G. Arliguie, "Effect of microcracking and cracking on the development of corrosion in reinforced concrete members," Magazine of Concrete Research, vol. 51, no. 2, pp. 143-150, 1999.

[3] Concrete Society, Non-Structural Cracks in Concrete, Concrete Society Technical Report No.22, Concrete Repair Manual, vol. 1, ACI, BRE, Concrete Society, International Concrete Repair Institute, London, UK, 2nd edition, 1992.

[4] E. Nolan, P. A. M. Basheer, and A. E. Long, "Effects of three durability enhancing products on some physical properties of near surface concrete," Construction and Building Materials, vol. 9, no. 5, pp. 267-272, 1995.

[5] S. O. Nwaubani and J. Dumbelton, "A practical approach to in-situ evaluation of surface-treated structures," Construction and Building Materials, vol. 15, no. 4, pp. 199-212, 2001.

[6] ACI Committee 224, Causes, Evaluation and Repair of Cracks in Concrete Structures, ACI Manual of Concrete Practice-Part 2, ACI International, 2002.

[7] JCI, Investigation, Evaluation and Repair of Cracks in Concrete Structures, Japanese Concrete Institute, 2003 (in Japanese).

[8] KISTEC, Specification on Repair of Cracks in Concrete Structures, Korea Infrastructure Safety \& Technology Corporation, 1999 (in Korean).

[9] NT Build 492, Concrete, Mortar and Cement-Based Repair Materials: Chloride Migration Coefficient from Non-Steady-State Migration Experiment, Nordtest, Espoo, Finland, 1999.

[10] J. G. Dai, Y. Akira, F. H. Wittmann, H. Yokota, and P. Zhang, "Water repellent surface impregnation for extension of service 
life of reinforced concrete structures in marine environments: the role of cracks," Cement and Concrete Composites, vol. 32, no. 2, pp. 101-109, 2010.

[11] I. S. Yoon and E. Schlangen, "Long/short term experimental study on chloride penetration in cracked concrete," Key Engineering Materials, vol. 417-418, pp. 765-768, 2010. 

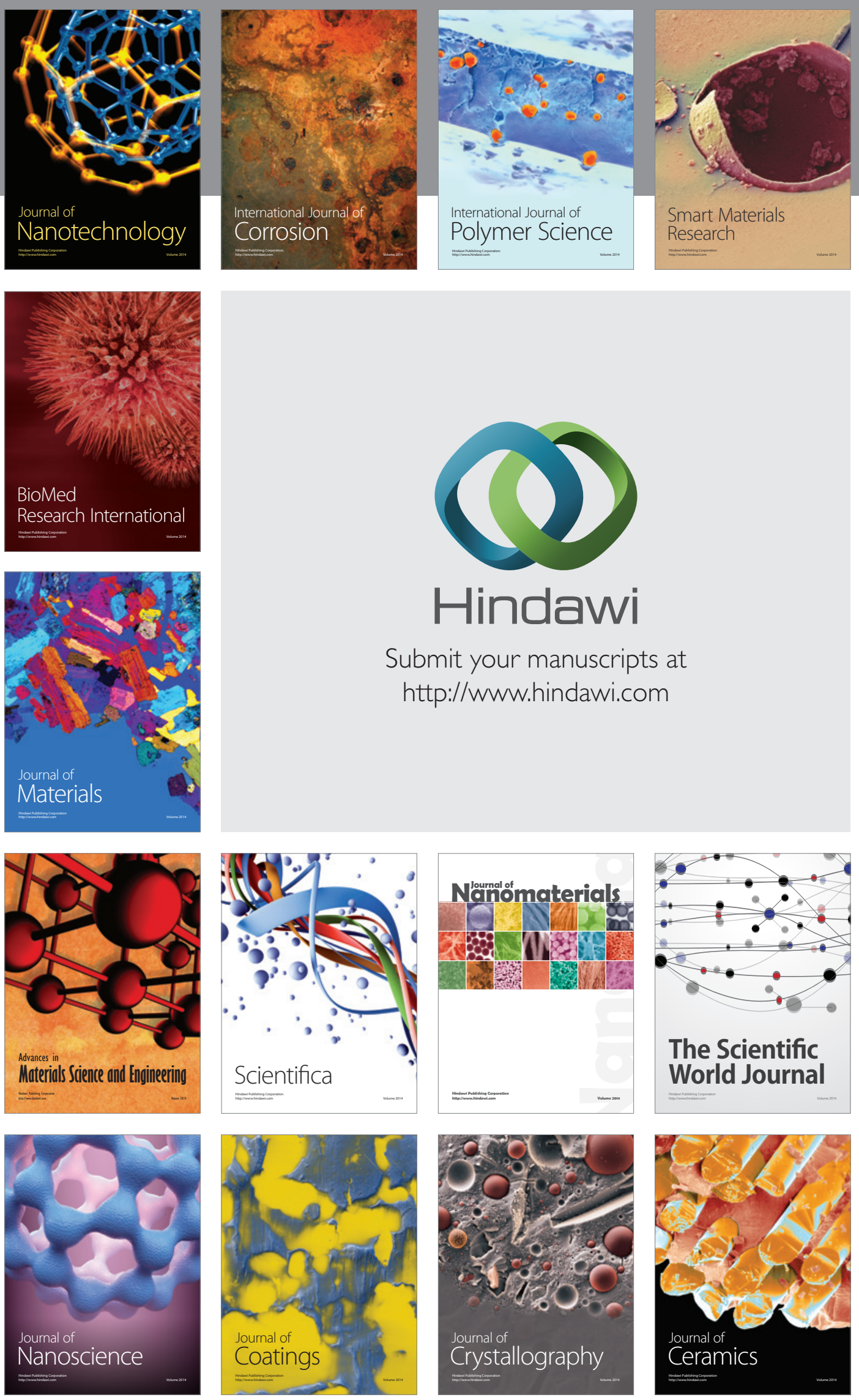

The Scientific World Journal

Submit your manuscripts at

http://www.hindawi.com

\section{World Journal}

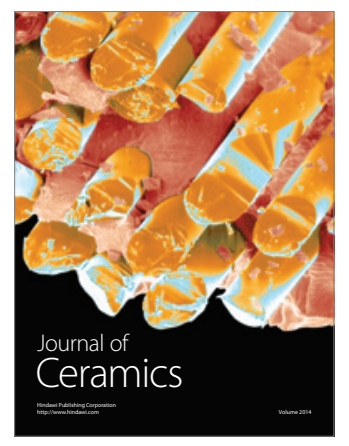

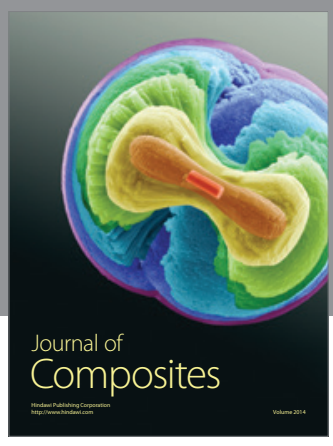
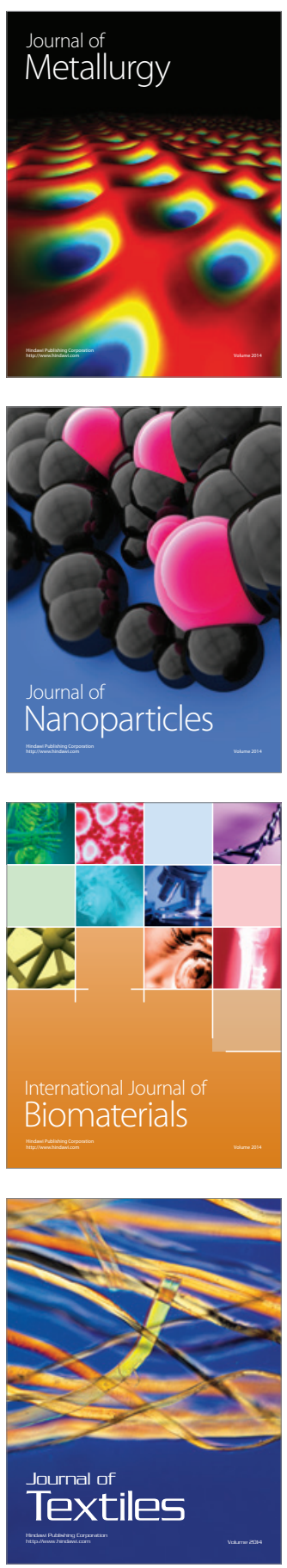